\title{
ANÁLISIS DEL ARGUMENTO DE BERKELEY PARA PROBAR LA EXISTENCIA DE DIOS (TRATADO SOBRE LOS PRINCIPIOS DEL CONOCIMIENTO HUMANO I, §29)
}

\author{
ANALYSIS OF BERKELEY'S ARGUMENT \\ TO PROVE THE EXISTENCE OF GOD \\ (A TREATISE CONCERNING THE PRINCIPLES \\ OF HUMAN KNOWLEDGE I, §29)
}

ALBERTO OYA MÁRQUEZ *

Investigador independiente

REsumen: En este ensayo analizaremos el argumento que usa Berkeley para probar la existencia de Dios en el Tratado sobre los principios del conocimiento humano I, $\$ 29$. Veremos cuál es la estructura del argumento, la justificación que ofrece Berkeley de sus premisas y expondremos los que creemos son los principales problemas del argumento. A partir de nuestro análisis, llegaremos a la conclusión de que el argumento es dialécticamente inútil, en tanto que sus premisas no están justificadas.

Palabras clave: Berkeley, existencia de Dios, voluntad, ideas de sensación, ideas de imaginación.

AвSTRACT: In this essay I will analyze the argument that Berkeley uses to prove the existence of God in A Treatise Concerning the Principles of Human Knowledge I, \$29. I

*alberto.oya.marquez@gmail.com 
will show the structure of the argument and the justification that Berkeley offers for its premises and I will explain what I think the main problems of the argument are. As a result of this analysis, I will arrive at the conclusion that the argument is dialectically useless, insofar as its premises are not justified.

KEYwORDs: Berkeley, existence of God, will, ideas of sensation, ideas of imagination.

\section{Introducción y consideraciones preliminares}

En este ensayo analizaremos el argumento que usa Berkeley para probar la existencia de Dios en el Tratado sobre los Principios del Conocimiento Humano (de ahora en adelante Principios) I, \$29. El argumento parece tener una importancia fundamental en la propuesta de Berkeley por dos razones: por un lado, permite preservar la objetividad de la percepción y, por otro lado, permite inferir de manera necesaria la existencia de Dios, lo cual constituye uno de los grandes objetivos del autor y que, al mismo tiempo, era según Berkeley una de las grandes deficiencias del materialismo.

Cabe decir, en primer lugar, que a lo largo de nuestras reflexiones no tendremos en cuenta el llamado "argumento de la continuidad», tanto porque creemos que no aparece en los Principios como porque no sirve a sus propósitos. Este argumento, que pretende probar la existencia de Dios, puede ser formulado como sigue:

(I) Dado que los objetos de percepción son colecciones de ideas (Berkeley. Principios I, \$1) y que sólo existe aquello que es percibido (Berkeley. Principios I, \$3), ningún objeto puede existir a no ser que sea percibido por algún espíritu -pues la existencia de una idea es su ser percibido.

(II) Hay objetos que existen cuando no son percibidos por ningún espíritu humano.

(III) Hay un espíritu no humano que percibe los objetos cuando ningún espíritu humano los está percibiendo. 
Este argumento no aparece de forma directa en los Principios: es cierto que en Principios I, \$45-48, Berkeley afirma que Dios podría percibir los objetos cuando no hay nadie más percibiéndolos, con la cual cosa se está dando una alternativa posible -que no justificada- a decir que el mundo está en un proceso constante de creación y destrucción, pero no es menos cierto que esto constituye sólo una posibilidad -y que, por tanto, no soluciona el problema de la continuidad ${ }^{1}-\mathrm{y}$ que no prueba la existencia de Dios, tan sólo la utiliza -se ve claramente que Dios es aquí solamente un recurso ad hoc para evitar el tener que decir que de la teoría de Berkeley se sigue necesariamente que el mundo está en un proceso constante de creación y destrucción. Por otro lado, el argumento falla a sus propósitos por la sencilla razón de que (II) -esto es: «Hay objetos que existen cuando no son percibidos por ningún espíritu humano»- no está justificada; de hecho, la consecuencia más natural del esse est percipi aut percipere berkelyano ("ser es percibir o ser percibido») parece ser precisamente su contraria.

Todo lo que diremos aquí es también independiente de la discusión, creemos que de carácter fundamentalmente teológico, acerca de si Dios sólo causa nuestras ideas de sensación o, además de causarlas, también las percibe $-\mathrm{y}$, por tanto, subsisten en Él. Tampoco entraremos a valorar, en el caso de que Dios cause y perciba nuestras ideas de sensación, si Dios percibe nuestras ideas sólo cuando nosotros las percibimos o si lo hace en todo momento. No obstante, con esto no queremos decir que ésta discusión carezca de valor y no sea útil para una mejor comprensión de la propuesta berkelyana. La cuestión por la continuidad de la que hablábamos en el parágrafo anterior, por ejemplo, depende de esta discusión: si Dios causa pero no percibe, o si causa y percibe sólo cuando nosotros percibimos, entonces es cierto que el mundo se encuentra en un constante proceso de creación y destrucción; si Dios causa y percibe siempre, entonces el mundo no se encuentra en tal situación. Lo que queremos decir es que estamos más interesados en analizar otros aspectos que consideramos anteriores a este tipo de discusiones y que son, de hecho, los que las fundamentan. Y es que no tiene sentido preguntarse por los atributos del Dios berkelyano sin preguntarse antes

${ }^{1}$ En caso de que esto se considere un problema para la filosofía de Berkeley. De hecho, creemos que la cuestión acerca de la continuidad del mundo no constituye realmente un problema para Berkeley: el afirmar o negar que hay objetos que existen aún cuando no son percibidos por ningún espíritu humano es totalmente independiente de la validez de su propuesta y de su tesis principal del esse est percipi aut percipere («ser es percibir o ser percibido»). Aunque también es cierto que afirmar que hay objetos que existen aún cuando no son percibidos por ningún espíritu humano podría hacer la propuesta de Berkeley más atractiva, en tanto que concordaría mucho más con el sentido común. 
si estamos legitimados a afirmar la existencia del mismo, siendo precisamente esto lo que estamos haciendo en este ensayo.

\section{Exposición del argumento}

El argumento que usa Berkeley en los Principios para probar la existencia de Dios se basa en la distinción de las que nosotros llamaremos ideas de sensación e ideas de imaginación, junto con la tesis de que toda idea es producto de una voluntad -o espíritu, en argot berkelyano.

Si observamos nuestra mente, ${ }^{2}$ dice Berkeley, veremos que en ella habitan dos tipos de ideas muy diferentes: las primeras, las ideas de imaginación, dependen exclusivamente de nuestra voluntad y son menos vivas y se muestran con menos coherencia que las segundas, las ideas de sensación, que no dependen de nuestra voluntad (Berkeley. Principios I, \$30). Las ideas de sensación suelen recibir el nombre de «cosas reales» («real things»: Berkeley. Principios I, \$33), mientras que las ideas de imaginación son llamadas «ideas» o «imágenes de cosas» («ideas or images of things»: Berkeley. Principios I, \$33), ya que las segundas tienen menos realidad que las primeras y son copias de estas; esto, pero, no significa que las ideas de sensación existan fuera de la mente, pues son ideas y como tales solamente pueden existir en una substancia pensante (Berkeley. Principios I, \$33).

Partiendo de esta distinción, y dando por supuesto que toda idea es producto de una voluntad, Berkeley ofrece su argumento:

Encuentro que puedo excitar ideas en mi mente cuanto desee, y que puedo variar y modificar el panorama cuantas veces crea conveniente. No hay más que desear, y ésta o aquella idea aparece directamente en mi imaginación; y por la misma facultad es borrada y cede el paso a otra idea. [...] Pero, sea cuál sea el poder que yo pueda tener sobre mis propios pensamientos, encuentro que las ideas que son de hecho percibidas por los sentidos no tienen tal dependencia respecto a mi voluntad. Cuando a plena luz del día abro mis ojos no está en mi poder escoger qué ver o qué no ver, ni tampoco determinar qué objetos particulares se presentaran a mi vista; lo mismo por lo que refiere al oído y a los otros sentidos; las ideas impresas en ellos no son

\footnotetext{
${ }^{2}$ Es decir: aplicando un criterio introspectivo.
} 
producto de mi voluntad. Hay, por tanto, algún otro Espíritu o Voluntad que las produce. (Berkeley. Principios I, $\$ 28$ y $\$ 29$. La cursiva es del autor)

La estructura del argumento anterior puede ser formulada, pues, de la manera siguiente:

(1) Toda idea es producto de una voluntad.

(2) Nuestras ideas de sensación no son producto de nuestra voluntad.

(3) Hay una voluntad diferente a nosotros que causa nuestras ideas de sensación.

Y esta voluntad a la que se hace referencia en (3), dice el autor, no puede ser otra que la de una voluntad o espíritu más potente que el nuestro -a saber: Dios-, pues las ideas de sensación son más potentes (tienen, como ya dijimos, más realidad, son más regulares, siguen un orden más coherente, etc.) que las ideas de imaginación, que son las que una voluntad finita como cada uno de nosotros es capaz de producir (Berkeley. Principios I, \$30).

Pues bien, tanto (1) como (2), pero sobre todo (1), requieren de justificación. Berkeley da una justificación intuitiva de (2): nos damos cuenta de que podemos cerrar los ojos e imaginar, a voluntad, que, por ejemplo, en nuestro despacho hay una sirena; pero no podemos percibir, a voluntad, que en nuestro despacho hay una sirena (Berkeley. Principios I, $\$ 28$ y $\$ 29)$. La justificación de (1) es diferente y se basa en el carácter pasivo que Berkeley cree que tienen las ideas y en el supuesto de que toda idea tiene una causa; en palabras del autor:

Todas nuestras ideas, sensaciones, nociones, o las cosas que percibimos, independientemente de los nombres con las que las distingamos, son visiblemente inactivas - no hay ningún poder o actividad incluido en ellas. De 
manera que una idea u objeto de pensamiento no puede producir o provocar ninguna alteración en otra. [...] Percibimos una sucesión continua de ideas, algunas aparecen de nuevo, otras son cambiadas o desparecen completamente. Hay, por tanto, alguna causa de estas ideas, de la que dependen, y que las producen y las cambian. Que esta causa no puede ser ninguna cualidad o idea, o ninguna combinación de ideas, resulta claro por la sección anterior. Debe haber, por tanto, una substancia; pero se ha mostrado que no hay una substancia corpórea o material: resta, por tanto, que la causa de las ideas sea una substancia activa e incorpórea o espíritu. (Principios I, \$25 y \$26)

La estructura de la justificación que Berkeley ofrece para la premisa (1) es, pues, la siguiente:

(i) Toda idea tiene una causa.

(ii) Las ideas son pasivas -esto es: no pueden ser la causa de nada.

(iii) No hay ninguna substancia material que pueda ser la causa de nuestras ideas.

(iv) Hay una substancia inmaterial y activa que causa nuestras ideas -esto es: (1) Toda idea es producto de una voluntad.

\section{Análisis del argumento}

El primer problema que presenta el argumento es que, des de la óptica berkelyana, no es posible justificar una premisa como (ii). Esto se debe al supuesto, presente no sólo en Berkeley sino en gran parte de la epistemología moderna, de que el sujeto perceptor mantiene únicamente una relación epistémica, por introspección, con sus ideas o imágenes internas, y aunque se presupone que tienen un origen causal, el conocimiento de éste resulta inaccesible, pues se halla fuera del único ámbito con el que el individuo puede entablar 
una relación epistémica, el de las ideas o imágenes internas. ${ }^{3}$ Dentro de esta concepción, la única forma de que la percepción sea también una relación epistémica entre el sujeto y la causa de sus ideas o imágenes internas -aunque de manera mediata- es postular el representacionalismo; es decir: afirmar que las imágenes internas del sujeto representan, ya sea de manera total o parcial y mediante una relación de semejanza o parecido, aquello que las causa. ${ }^{4}$ Berkeley, sin embargo, al haber postulado el conocido como principio de semejanza (likeness principle), ${ }^{5}$ no puede aceptar tal propuesta. En conclusión: dentro del paradigma de la epistemología moderna, y también en el caso concreto de Berkeley, no podemos derivar que las ideas sean pasivas porque no veamos que causen otras ideas, pues no vemos nunca, por definición, qué es lo que causa las ideas. ${ }^{6}$

La segunda dificultad que presenta el argumento refiere al posible contenido de la idea de causa. Berkeley podría insistir aquí en que todo el contenido de la idea de causa se deriva de la introspección; esto es: percibimos introspectivamente que nuestra voluntad causa ciertas ideas. Esta respuesta, pero, presenta dos problemas.

En primer lugar, si todo el contenido de la idea de causa es nuestra voluntad causando ciertas ideas, ¿cómo aplicamos este contenido a la idea de otro espíritu o voluntad produciendo nuestras ideas? Es decir: el contenido de

3 Mientras que en el caso de Berkeley el origen de nuestras ideas o imágenes internas se encuentra en una voluntad o espíritu de carácter inmaterial, para la mayoría de filósofos de época moderna -es el caso de Locke, Descartes y Hobbes, por ejemplo- la causa de nuestras ideas es el mundo externo de carácter físico.

${ }^{4}$ Esta es la propuesta de John Locke en su Ensayo sobre el entendimiento humano (1690) y que se articula a partir de la distinción entre dos tipos de ideas: las ideas de cualidades primarias (ideas particulares de solidez, extensión, figura, movimiento o reposo, y nombre) y las ideas de cualidades secundarias (ideas particulares de color, olor, sonido y sabor). Locke concluirá que las ideas de cualidades primarias representan fielmente las características del mundo externo, mientras que las ideas de cualidades secundarias no hacen tal cosa.

5 El principio de semejanza (likeness principie) es formulado por Berkeley en Principios I, $\$ 8$ como sigue: «[...] una idea no puede parecerse a nada si no es a otra idea [...]». El principio niega, por tanto, que el contenido de nuestras ideas pueda representar nada fuera del ámbito de las ideas; de hecho, lo que pretende mostrar es la incompatibilidad del propio concepto de representación con la noción de idea que emplea la epistemología moderna.

${ }^{6}$ De hecho, se trata de algo que el propio Berkeley parece reconocer cuando afirma que «[...] no puede haber ninguna idea de alma o espíritu; pues todas las ideas, sean cuáles sean estas, siendo pasivas e inertes (véase sección 25), no pueden representarnos, mediante imagen o semejanza, aquello que actúa.» (Berkeley. Principios I, \$27). 
nuestra idea de causa es nuestra propia voluntad produciendo ideas en ella misma, y no la de otra voluntad diferente a ella produciendo ideas en nosotros -siendo éste último el contenido de la idea de causa que Berkeley usa en el argumento de Principios I, $\$ 29$.

En segundo lugar, y mucho más importante, el contenido de nuestra idea de causa parece no ser otro que la idea de una voluntad produciendo ideas. Diríamos, no obstante, que esto es algo que Berkeley no puede aceptar, en tanto que siendo las ideas pasivas y dado el principio de semejanza, las ideas no pueden representar nada que sea activo -como es el caso de una voluntad. En todo caso deberíamos decir que esta voluntad no es otra cosa que una idea, pero entonces nos encontraríamos con que el contenido de nuestra idea de causa es sólo una sucesión, una idea que va seguida de otras ideas. Sin embargo, esta idea de causa como sucesión de ideas, independientemente de si es correcta o no, no es válida para los usos que Berkeley pretende con el argumento anterior.

\section{Conclusión}

La conclusión que podemos extraer de nuestro análisis es que el argumento usado en Principios I, $\$ 29$ es dialécticamente inútil, en tanto que sus premisas no están justificadas. A raíz de nuestro análisis parece que también podemos llegar a la conclusión de que este argumento, y, en un sentido más amplio, la existencia de Dios, es independiente de la validez de la propuesta inmaterialista berkelyana: es cierto que rechazar la intervención divina provocaría cierta clase de subjetivismo perceptivo -en el sentido de que estaríamos obligados a aceptar que todas las ideas de percepción son fruto de la voluntad individual que las percibe-, pero su tesis principal -el esse est percipi aut percipere- no se ve afectado por la falta de intervención divina.

\section{Agradecimientos}

El presente artículo está dedicado a Julio y a Dolores. 


\section{Bibliografía}

Barnes, W. H. F. “Did Berkeley Misunderstand Locke?”; en: Creery, Walter E. (ed.) (1991). George Berkeley: Critical Assessments. (Volumen II: "Qualities, General Ideas and Perception”). Londres: Routledge. Págs. 23-28.

Beardsley, Monroe C. "Berkeley on "Abstract Ideas"”; en: Martin, C.B., Amstrong, D.M. (eds.) (1968). Locke and Berkeley: A collection of Critical Essays. Londres: Macmillan. Págs. 409-425.

Bennett, J. (1991). Locke, Berkeley, Hume: Central Themes. (7a ed.) Hong Kong: Oxford University Press.

— "Berkeley and God"; en: Martin, C.B., Amstrong, D.M. (eds.) (1968). Locke and Berkeley: A collection of Critical Essays. Londres: Macmillan. Págs. 380-399.

Berkeley, George (2003/1710). A Treatise concerning the Principles of Human Knowledge. USA: Dover Publications.

Broad, C. D. "Berkeley's Denial of Material Substance"; en: Martin, C.B., AmsTrong, D.M. (eds.). (1968). Locke and Berkeley: A collection of Critical Essays. Londres: Macmillan. Págs. 255-283.

Copleston, F. (2001). Historia de la Filosofía (volumen 5: "De Hobbes a Hume”). (4a ed.). Barcelona: Ariel.

Davidson, Arnold I.; Hornstein, Norbert. "The Primary/Secondary Quality Distinction: Berkeley, Locke and the Foundations of Corpuscularian Science"; en: CreERY, Walter E. (ed.) (1991). George Berkeley: Critical Assessments. (Volumen II: "Qualities, General Ideas and Perception”). Londres: Routledge. Págs. 96-121.

Descartes, René (2005/1641). Meditacions Metafísiques. (2a ed.). Barcelona: Edicions de 1984.

Downing, Lisa. "Berkeley”. Stanford Encyclopedia of Philosophy. Febrero 2014. http:// plato.stanford.edu/entries/berkeley/

Fogelin, Robert J. (2001). Routledge Philosophy GuideBook to Berkeley and the Principles of Human Knowledge. Febrero 2014. http://englishstudentsforum.com/uploads/English\%20related/Routledge Philosophy Guidebook to Berkeley.pdf

Furlong, E. J. "Berkeley and the Tree in the Quad"; en: Martin, C.B., Amstrong, D.M. (eds.) (1968). Locke and Berkeley: A collection of Critical Essays. Londres: Macmillan. Págs. 400-408.

García SÁnchez, Esmeralda (1995). John Locke (1632-1704). Madrid: Ediciones del Orto.

“George Berkeley (1685-1753)”. Internet Encyclopedia of Philosophy. Febrero 2014. http://www.iep.utm.edu/berkeley/ 
González Gallego, Agustín (1984). Locke. Empirismo y experiencia. Barcelona: Editorial Montesinos.

Hume, David (1978/1739). A Treatise of Human Nature. 2a ed. China: Oxford University Press, 1978.

“John Locke (1632-1704)”. Internet Encyclopedia of Philosophy. Febrero 2014. http:// www.iep.utm.edu/locke/

Locke, John (1990/1690). An Essay concerning Human Understanding. Hong Kong: Oxford University Press.

Маввотт, J. D. “The Place of God in Berkeley's Philosophy”; en: Martin, C.B., AmsTrong, D.M. (eds.) (1968). Locke and Berkeley: A collection of Critical Essays. Londres: Macmillan. Págs. 364-379.

Marc-Wogau, Konrad. “The Argument from Illusion and Berkeley's Idealism”; en: Creery, Walter E. (ed.) (1991). George Berkeley: Critical Assessments. (Volumen II: "Qualities, General Ideas and Perception”). Londres: Routledge. Págs. 328-337.

Quintanilla, Ignacio (1995). George Berkeley (1685-1753). Madrid: Ediciones del Orto.

Stroud, Barry. "Berkeley v. Locke on Primary Qualities"; en: Creery, Walter E. (ed.) (1991). George Berkeley: Critical Assessments. (Volumen II: "Qualities, General Ideas and Perception"). Londres: Routledge. Págs. 45-62.

Ursom, J. O. (1984). Berkeley. Madrid: Alianza Editorial.

UzGalis, William. “John Locke”. Stanford Encyclopedia of Philosophy. Febrero 2014. http://plato.stanford.edu/entries/locke/

Recibido: 3/03/2014

Aceptado: 29/05/2014

Este trabajo se encuentra bajo una licencia de Creative Commons ReconocimientoNoComercial-SinObraDerivada 4.0

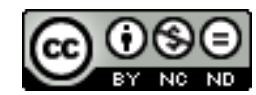

